\title{
Linking with Mtwara, Tanzania: a personal view on skill sharing for sexual health
}

\author{
Paula Baraitser, Susan Mann
}

\section{Background}

Mtwara, in the southernmost part of Tanzania, is a bustling but remote town, little known by tourists, in a stunningly beautiful part of the eastern coast and bordering on Mozambique. It suffers from the legacy of a failed groundnut scheme that was planned in the early 1950s and abandoned, and it has the feeling of a town waiting to happen. Adequate communication links with the rest of Tanzania were never established and the promised economic prosperity never arrived.

This region had been identified as one where there may be gains from partnership development between a group of National Health Service (NHS)-based sexual and reproductive health professionals in London, UK, and those delivering sexual and reproductive health services in Tanzania. Hence, in December 2006 the authors made their first reconnaissance visit, funded by Voluntary Services Overseas (VSO), and embarked on the process of relationship building and identifying priority areas for action.

Poverty is the major human development problem in Tanzania and, consequently, the main impediment to health improvement. It is estimated that approximately $51 \%$ of the population are living below the poverty line on less than US $\$ 1$ a day and $30 \%$ of them are considered to be in absolute poverty. ${ }^{1}$

\section{Sexual health issues}

The Mtwara Regional Health Team meeting was reassuringly familiar. Their list of sexual health priorities (improving sexual health among young people, reducing teenage pregnancy and increasing access to long-acting methods of contraception) was very similar to the authors' own list of priorities in London. We discussed outreach programmes that link clinics with schools and the "pros and cons' of long-acting methods where access to services is difficult.

The feeling that we knew the territory stopped when we discussed the impact of sexual health services on maternal mortality. The maternal mortality rate in Tanzania is 10 per 10000 women aged 15-49 years. Furthermore, for every 10000 live births in Tanzania during the period 1999-2005, 60 women died of pregnancy-related causes. ${ }^{2}$ In the UK, maternal mortality is 1 per 10000 live births. ${ }^{3}$ In the Tanzanian context the impact of developing family

J Fam Plann Reprod Health Care 2007; 33(2): 119-120

Lambeth and Southwark Sexual Health Modernisation Programme, London, UK

Paula Baraitser, MD, MFFP, Specialist Registrar in Public Health Medicine

Department of Public Health, City and Hackney Primary Care Trust, Health Improvement, St Leonards Hospital, London, UK

Susan Mann, MRCOG, MFFP, Specialist Registrar in Public Health Medicine

Correspondence to: Dr Paula Baraitser, Lambeth and Southwark Sexual Health Modernisation Programme, Masters House, Dugard Way (off Renfrew Road), London SE11 4TH, UK. E-mail: paula_baraitser@mac.com planning services is on mortality. When we seek funding for service development in London we talk about morbidity and quality of care.

In Tanzania, 26\% of women are using some form of contraception. Use of modern methods has increased slightly from $17 \%$ in 1999 to $20 \%$ in 2004-2005, yet paradoxically $69 \%$ of married women say that they either want to delay the birth of their next child or have no more children. The most commonly used modern methods are the pill $(6 \%)$ and injectables (8\%). Use of contraception increases with educational attainment, and in general women do not start using contraception until they have had at least one child. ${ }^{2}$

The prevalence of HIV/AIDS in Tanzania is $8.8 \% .{ }^{4}$ The disease is currently imposing an ever-increasing burden on the country's financial resources through rising medical expenditure, absenteeism from work and labour shortages resulting from morbidity and mortality. The Tanzanian Demographic Health Survey indicates that high-risk sexual behaviour continues despite high levels of knowledge about HIV/AIDS and how to prevent it. For example, it shows that $46 \%$ of never-married but sexually active men aged 15-24 years used a condom at their last sexual encounter. ${ }^{2}$

\section{Mtwara/London partnership}

The idea for this link came from the Tropical Health Education Trust (www.thet.org.uk), an organisation that supports institution-to-institution partnerships between NHS organisations and their counterparts in developing countries. The NHS organisation fundraises on behalf of the link and releases staff for short periods to do clearly defined targeted pieces of work abroad. The link remains in place over many years and the skill-sharing programme is therefore sustainable. Links are often in areas of health that are relatively underserved by the international community. In Mtwara there is considerable international presence in the field of HIV, but very little in sexual and reproductive health despite its potential impact on mortality and morbidity. The NHS organisation benefits from personal development opportunities for its staff. Working in another country increases job satisfaction, provides new clinical opportunities and experience of working in resource-poor settings.

What is new about this link is the emphasis on a specialist subject. Any single sexual health department is probably too small to sustain a substantial link over many years so the idea is to link a network of sexual health professionals from several departments with their colleagues in a developing country. Similar specialist links are being piloted in urology and psychiatry but the authors know of no other link for sexual health. We would like to see similar links piloted in different areas in order to understand how skill sharing in this context might work.

There was great enthusiasm for the partnership in Mtwara. Three areas for collaboration have been identified. In each case the work is consistent with Tanzanian national strategy and would be delivered by sexual health professionals in Mtwara anyway. We can add value by delivering (free of charge) additional targeted work such as needs assessment, evaluation, teaching, new ideas from our 


\section{Baraitser and Mann}

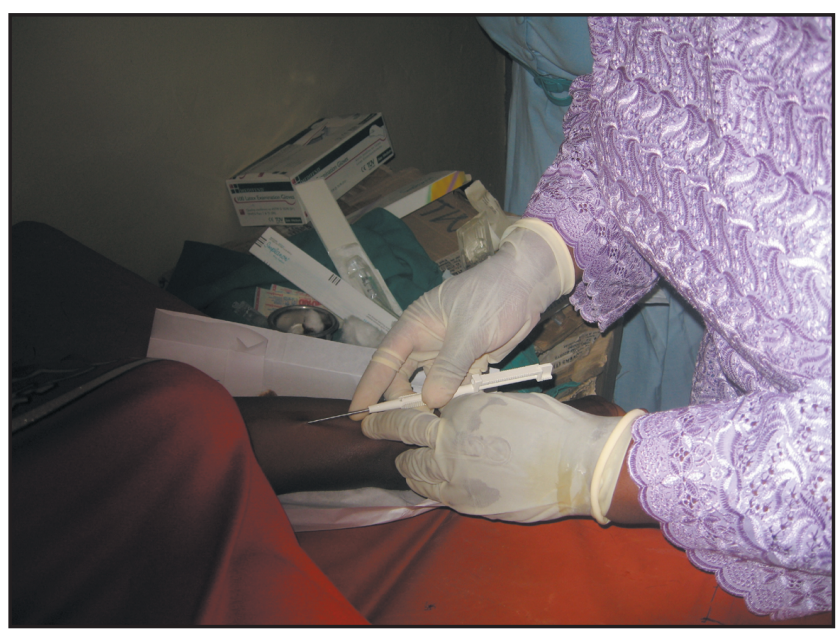

Figure 1 Fitting an implant in Mtwara: the scene looks familiar to any family planning doctor

experience of sexual health service development in London, management support for specific projects and (if we fundraise successfully) targeted resources. In return we will get to see new ways of working and we will be inviting sexual health professionals from Mtwara to London to discuss their experience of syndromic management of sexually transmitted infections and community-based family planning distribution. Decisions about the management of the link are made jointly by the Regional Health Team in Mtwara and the network steering group in London.

The sense of both familiarity and difference remained throughout the trip. The first photograph (Figure 1) could have been taken in either London or Mtwara. It is only when the photographer stands back and gives us a wider view (Figure 2) that it becomes clear how different the context really is.

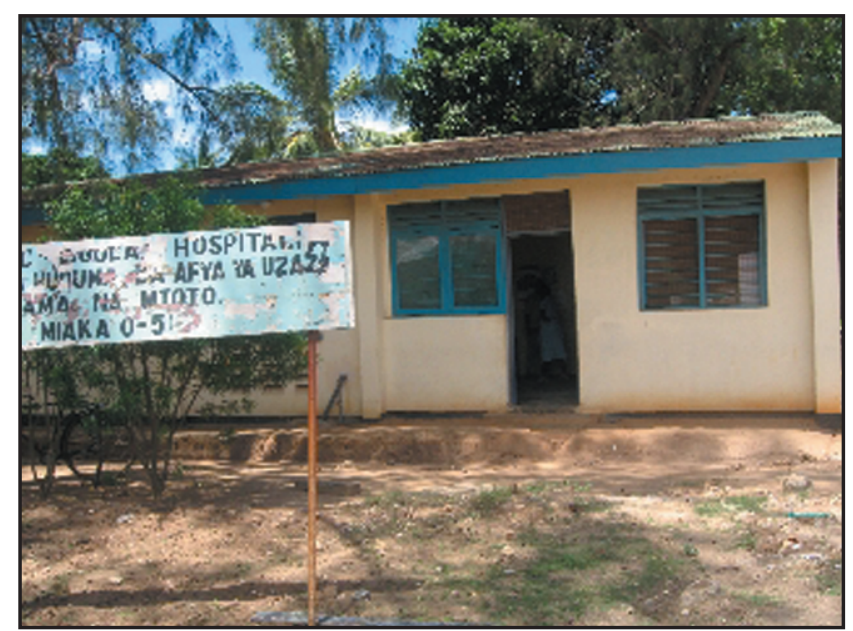

Figure 2 The building in which this service was provided shows how different the context really is

\section{Authors' note}

Paula Baraitser and Sue Mann visited Mtwara region, Tanzania for 3 weeks in December 2006 to do a feasibility study for VSO on a potential sexual health link.

Statements on funding and competing interests

Funding The authors' visit to Mtwara, Tanzania was funded by VSO.

\section{Competing interests None identified.}

References

1 World Health Organization (WHO). WHO Country Cooperation Strategy, 2002-5. United Republic of Tanzania. Geneva, Switzerland: WHO, 2002.

2 National Bureau of Statistics. The 2004-05 Tanzania Demographic and Health Survey. Dar Es Salaam, Tanzania: National Bureau of Statistics, February 2005.

3 World Health Organization (WHO). World Health Report (2006 edn). Geneva, Switzerland: WHO, 2006.

4 Asamoah-Odei E, Garcia Calleja J, Boerma J. HIV prevalence and trends in sub-Saharan Africa. Lancet 2004, 364: 4-6. 